Article

\title{
Impacts of Climate Change and Climate Variability on Hydropower Potential in Data-Scarce Regions Subjected to Multi-Decadal Variability
}

\author{
Pedro Arriagada ${ }^{1, *}$, Bastien Dieppois ${ }^{2,3,4}$, Moussa Sidibe ${ }^{2}$ and Oscar Link ${ }^{5}(\mathbb{C}$ \\ 1 Environmental Engineering Department, Universidad de Concepción, Concepcion 4070386, Chile \\ 2 Centre for Agroecology, Water and Resilience (CAWR), Coventry University, Coventry CV1 5FB, UK \\ 3 Department of Oceanography, University of Cape Town, Rondebosch 7701, South Africa \\ 4 School of Geography, Earth and Environmental Sciences, University of Birmingham, \\ Birmingham B15 2SA, UK \\ 5 Civil Engineering Department, Faculty of Engineering, Universidad de Concepción, \\ Concepcion 4070386, Chile \\ * Correspondence: parriagada@udec.cl; Tel.: +56-41-2204065
}

Received: 18 June 2019; Accepted: 15 July 2019; Published: 18 July 2019

\begin{abstract}
To achieve sustainable development of hydroelectric resources, it is necessary to understand their availability, variability, and the expected impacts of climate change. Current research has mainly focused on estimating hydropower potential or determining the optimal locations for hydropower projects without considering the variability and historical trends of the resources. Herein, the hydropower potential variability from reconstructed streamflow series estimated with a non-parametric gap-filling method and geographic information systems (GIS) techniques are analyzed. The relationships between hydropower and large-scale climate variability, expressed by sea surface temperature, are explored. Finally, we project hydropower potential through 2050 using 15 global circulation models with representative concentration pathway (RCP) 4.5. We used four watersheds in central Chile as a case study. The results show significant interannual and inter-basin hydropower potential variability, with decreasing trends over time modulated by alternating positive and negative decadal trends; these modulations exhibit greater intensities than the general trends and are attributable to climatic oscillations such as El Niño. Future scenarios indicate high hydropower availability and a possible over-investment in hydroelectric plants in two of the four studied watersheds. Results show the need to improve the current policies that promote hydropower development including hydropower resource variability in order to achieve optimal, sustainable hydropower development worldwide.
\end{abstract}

Keywords: hydropower potential variability; future hydropower scenarios; climate variability; climate oscillations

\section{Introduction}

The world is facing increasing energy demands as a direct consequence of population growth, urbanization, and industrialization. According to the International Energy Agency [1], world gross electricity production reached $25,082 \mathrm{TWh}$ in 2016. In addition, two thirds of electricity generation is based on fossil fuels, with corresponding $\mathrm{CO}_{2}$ emissions of about 32 million tons, accounting for about $25 \%$ of the total global emissions contributing to global warming. To mitigate the effects of climate change, local governments worldwide have been promoting the development of renewable energies through subsidiary policies such as clean development mechanisms and carbon credits [2]. As a result, renewable energies, especially hydropower [3], are undergoing a boom due to their simple engineering, 
greater efficiency, low energy production cost considering long effective lifetimes, and low operating and maintenance costs [4]. Worldwide hydropower potential is estimated at ca. 16,000 TWh [5], and hydropower reached the milestone of 1,000 GW of installed power in 2013. In recent years, the growth of the sector has ranged between $3 \%$ and $4 \%$. At this rate, hydropower capacity will double by the late 2030s, with substantial growth expected in Asia, Africa, and South America [6]. The effects of climate variability and climate change on water resources, and thus on hydropower potential, introduce important uncertainties that need to be estimated through a proper modelling framework [7]. Naturally, even marginal improvements in the estimation of the installed capacities of hydropower plants could lead to substantial economic and environmental benefits.

Estimation of hydropower, i.e., the product of the specific weight of water, streamflow, and net water head, must include spatio-temporal streamflow and water head patterns. Streamflow is controlled by atmospheric variables such as precipitation and temperature, as well as watershed properties (e.g., topography, soil types, and land covers), which together determine surface runoff production. The link between variables controlling hydropower with climate is not trivial. Precipitation, which depends on atmospheric circulation dynamics and orographic effects, is the main driver of streamflow variability [8]. Fabry [9] analyzed the temporal variability of precipitation, proposing that at low-frequency scales, i.e., interannual to centennial, precipitation is controlled by climatic variability, i.e., climatic oscillations. Multiple later works have explored the connections between climatic oscillations and precipitation; e.g., precipitation variability in South America is primarily driven by El Niño South Oscillation (ENSO) at the interannual time-scale and by the Pacific Decadal Oscillation (PDO), Atlantic Multi-Decadal Oscillation (AMO), and the Southern Annular Mode (SAM) at the decadal time-scale [10]. In addition, the temporal variability of water head, which is smaller than that of streamflow, can exhibit long-term dynamics due to gradual geological processes such as tectonics, erosion, and sediment transport or due to singular catastrophic events such as volcanism and mega-earthquakes [8].

The effect of climate oscillations on hydropower is a recent line of research; e.g., $\mathrm{Ng}$ et al. [11] showed that El Niño (ENSO) climate oscillation strongly influences global hydropower production and causes hydropower production anomalies in South America ranging from $-30 \%$ to $+30 \%$ between the different phases. Moreover, the effects of future climate change on hydropower resources introduce another major source of uncertainty for the development of the sector; for instance, van Vliet et al. [7] and Zhang et al. [6] suggest an increase in hydropower potential in the high latitudes of the Northern Hemisphere (North of $55^{\circ}$ latitude) and tropical Africa and a decrease in the US, Southern Africa, Europe and Southern Latin America. Carvajal et al. [12] estimated uncertainty in annual hydropower generation in Ecuador due to climate change at between $-55 \%$ and $+39 \%$ with respect to the average historical production. Turner et al. [13] showed that there is no clarity regarding the impacts of climate on hydropower in Latin America, which increases or decreases depending on the specific basin. This absence of consensus highlights a clear need to generate future hydropower scenarios considering the effects of climate variability and change at a reduced scale of analysis, e.g., basin level, to generate sustainable hydropower development policies [5].

In current practice, hydropower potential is estimated by combining geographic information systems (GIS) and hydrology techniques with different levels of complexity at the planetary [5], continental [14], and national and local $[15,16]$ scales. Streamflow is determined using surface-runoff hydrological models, from simplified empirical lumped models to watershed-specific distributed hydrological models. The main difficulties of these techniques are: i) The accurate representation of the hydrological processes in runoff generation using simplified models and ii) the availability of the required data for physically-based distributed or semi-distributed modelling, especially for large and data-scarce regions with complex configurations (e.g., orographic effects) [17]. Alternatively, streamflow variability can be obtained by interpolation of existing stream gauge data over the river networks [18]. However, relatively long data series are required to properly represent the different time scales of variability (e.g., intraseasonal to decadal). Gap-filling techniques are thus a good 
alternative for reconstructing streamflow, especially in data-scarce regions. Suitable methods such as those presented in Breiman [19] and Stekhoven and Bülmann [20] enable uncertainty in hydropower potential estimation to be reduced.

The impacts of climate change on hydropower potential have been evaluated through streamflow projections, which are obtained from hydrological models that use the downscaling projections for precipitation and atmospheric temperature from global circulation models (GCMs) [21]. However, there are errors and uncertainties associated with the precipitation-runoff modelling in hydropower estimations and projections, especially in a data-scarce region [17]. An alternative method to explore and project hydropower resources in these regions is necessary for their sustainable management. In this paper, we hypothesize that the variability of hydropower potential over the lifetime of a hydropower project, i.e., a couple of decades, and in a local area, i.e., basin scale, can be explained by streamflow variability, which in turn is controlled by climate variability, i.e., climate oscillations and trends. If this is the case, future hydropower scenarios can be determined from correlations between observed hydropower potential and sea-surface temperature (SST), and SST projections, obtained from GCM outputs, which will allow us to evaluate the impacts of climate change on hydropower potential in a specific basin. In particular, we evaluate the impacts of climate variability and change on hydropower potential in four major basins of central Chile (in which $76 \%$ of the country's hydropower development is concentrated). The observed hydropower potential was estimated from 1970 to 2016, using geographic information system (GIS) techniques and reconstructed daily flow series. The interannual variability of hydroelectric resources was correlated with four climate indices and global-scale gridded SST data. The future hydropower scenarios through 2050 were developed for each basin using the SST projections from 15 GCMs forced with representative concentration pathway (RCP) 4.5 , based on the correlations found between SST and observed hydropower potential for each basin.

\section{Study Area}

\subsection{Hydropower Development in Chile}

Due to population and economic growth in Chile, gross electricity generation exhibited a sustained increase from 22.4 TWh in 1996 to 75.5 TWh in 2018, with an expected annual growth rate of 2.5\% through 2035 [22]. In 1997, 76\% of the country's electricity was generated by hydropower. A severe drought in 1998 caused electric rationing and motivated the generation of electricity using fossil fuels, principally imported natural gas [23]. From that time, the use of hydropower decreased to $27 \%$ in 2016 [22]. In line with international concerns about climate change, Chile started to promote renewable energies (according to the Chilean regulatory framework, renewable energy sources include hydropower plants with installed power of up to $20 \mathrm{MW}$ ) with laws 20,257 in 2008, and 20,698 in 2013, which are also known as non-conventional renewable energy laws (NCRE). The first forced electricity companies with more than $200 \mathrm{MW}$ of installed power that make energy withdrawals from the interconnected system to prove that $10 \%$ of the withdrawals are from renewable sources. The second increased this fraction from 10 to $20 \%$. The implementation of these two laws caused an explosion of small hydropower plant (SHP) development in the country (Figure 1), as 27 new SHP were built between 2008 and 2012, with $60 \%$ of these plants located in four basins of central Chile (Maipo, Maule, Bío Bío, and Bueno rivers). In addition, 38 new SHP were built between 2012 and 2016, almost exclusively in these four basins. Furthermore, hydropower development in the country is expected to be concentrated in the Bío Bío and Bueno basins [24]. 


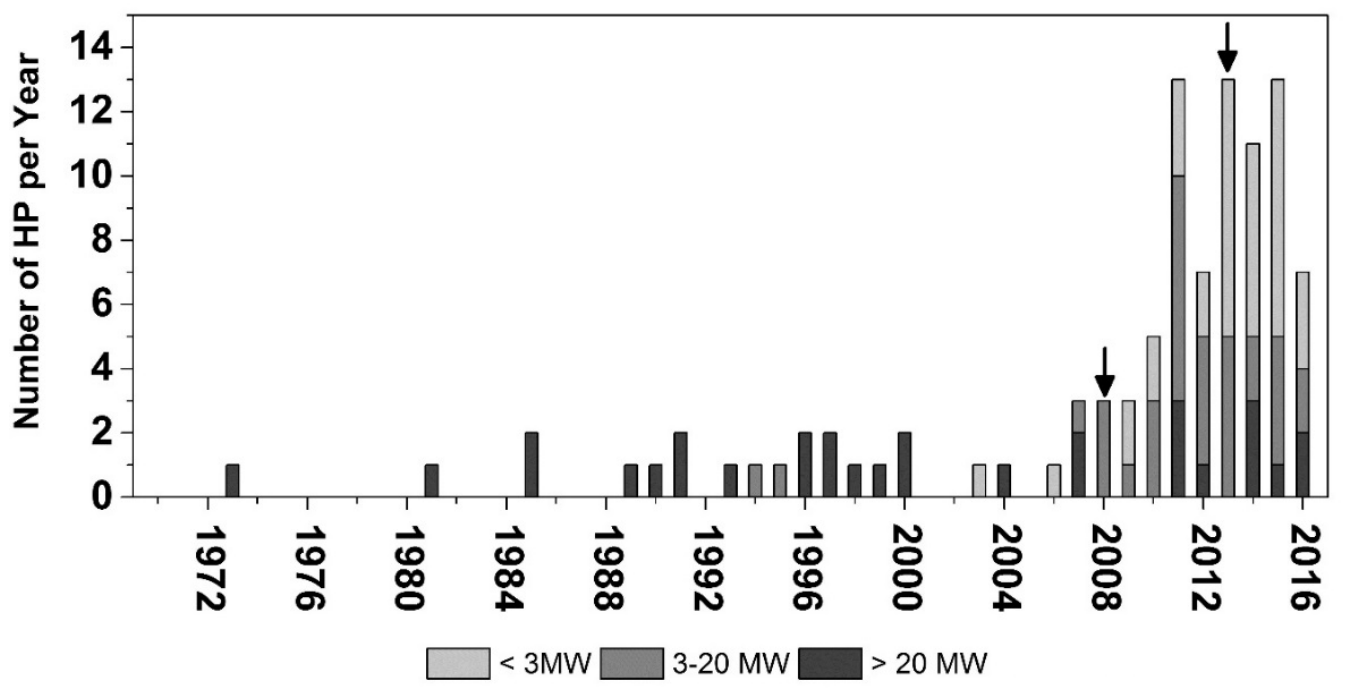

Figure 1. Installed hydropower plants (HP) in Chile between 1970 and 2016. Arrows indicate years of non-conventional renewable energy laws (NCRE) policy implementation.

In 2015, the Chilean Ministry of Energy estimated the exploitable hydropower of the country at $12 \mathrm{GW}$, spread among 1200 sites [25]. For this estimation, the flow was estimated with the variable infiltration capacity (VIC) hydrological model [26], and water head was computed as the altitude difference between the water intake and restitution of each site. Only sites with exploitable hydropower were considered in the analysis, i.e., sites which have already been assigned water rights for hydropower production [27], but without considering hydropower potential variability and trends. Currently, Chile aims to satisfy at least 70\% of its electricity demand with renewable energies by 2050 [28].

\subsection{Study Basins}

The study area is composed of four major basins in Chile located between 32.55 and $41.17^{\circ} \mathrm{S}$, with a surface area of about $15,000 \mathrm{~km}^{2}$ [29] and maximum altitudes ranging between 2410 and $6546 \mathrm{~m}$, from the Pacific Ocean to the Andes. These basins include 91 of the 148 existing hydropower plants in Chile, with a total power of $5.05 \mathrm{GW}$, i.e., $76 \%$ of the national installed hydropower [24]. In addition to these existing projects, 30 new hydropower plants with $0.65 \mathrm{GW}$ are under environmental evaluation or construction. Figure 2 shows the location of the study area, existing hydropower plants, and hydropower plants under evaluation.

According to Köppen's classification, the region is primarily characterized by warm temperature with winter rainfall $(\mathrm{Csb})$ between $30^{\circ}$ and $38^{\circ} \mathrm{S}$ and by warm temperature with rainfall and Mediterranean influence ( $\mathrm{Cfsb}$ ) between $38^{\circ}$ and $42^{\circ} \mathrm{S}$ [30]. Precipitation increases with latitude and altitude between $30^{\circ}$ and $40^{\circ} \mathrm{S}$. The rivers in the area are steeply graded and show great potential for hydroelectric energy production with mean annual discharges at their mouths ranging between 134 and $971 \mathrm{~m}^{3} / \mathrm{s}$ [31]. Table 1 shows the main hydro-climate parameters of the four basins. In addition, climate variability in the area is dominated by ENSO at the interannual scale and the interdecadal oscillations of the PDO, AMO, and SAM [32]. 


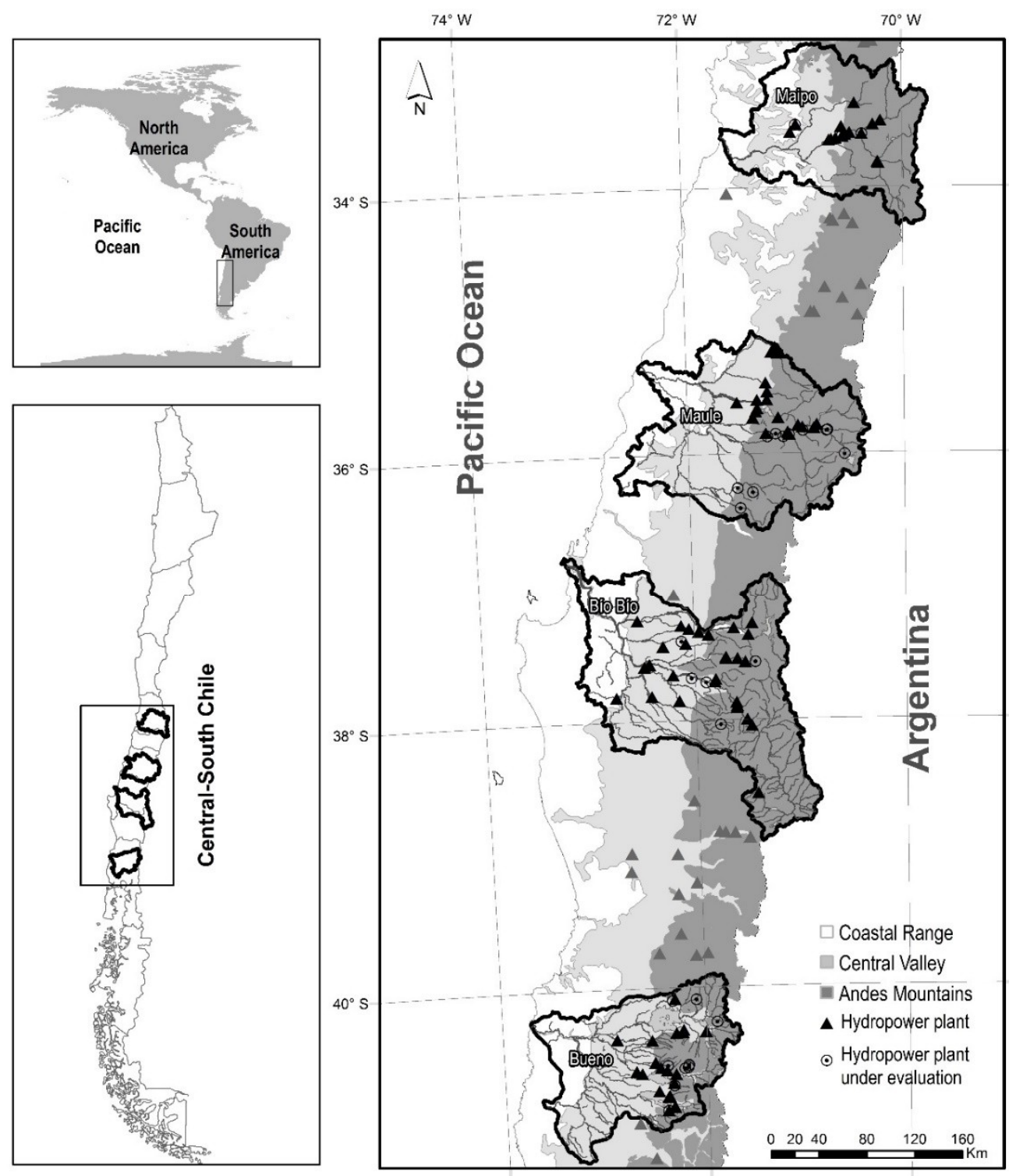

Figure 2. Location of the study area and installed and planned hydropower plants.

Table 1. Location, geomorphological and climate data for each basin in the study area.

\begin{tabular}{cccccccc}
\hline Basin & Latitude $\left({ }^{\circ}{ }^{\prime}\right)$ & Longitude $\left.\left(^{\circ}\right)^{\prime}\right)$ & $\begin{array}{c}\text { Area } \\
\left(\mathbf{k m}^{2}\right)\end{array}$ & $\begin{array}{c}\text { Andean } \\
\text { Area }\left(\mathbf{k m}^{2}\right)\end{array}$ & $\begin{array}{c}\text { Maximum } \\
\text { Height }(\mathbf{m})\end{array}$ & $\begin{array}{c}\text { Dominant } \\
\text { Climate }\end{array}$ & $\begin{array}{c}Q_{M A} \\
\left(\mathbf{m}^{3} / \mathbf{s}\right)\end{array}$ \\
\hline Maipo & $32^{\circ} 55^{\prime}-34^{\circ} 18^{\prime} \mathrm{S}$ & $69^{\circ} 48^{\prime}-71^{\circ} 38^{\prime} \mathrm{W}$ & 15,273 & 7781 & 6546 & $\mathrm{Csb}$ & 134 \\
\hline Maule & $35^{\circ} 06^{\prime}-36^{\circ} 35^{\prime} \mathrm{S}$ & $70^{\circ} 21^{\prime}-72^{\circ} 27^{\prime} \mathrm{W}$ & 21,052 & 10,163 & 3,931 & $\mathrm{Csb}$ & 495 \\
\hline Bío Bío & $36^{\circ} 52^{\prime}-38^{\circ} 54^{\prime} \mathrm{S}$ & $70^{\circ} 50^{\prime}-73^{\circ} 12^{\prime} \mathrm{W}$ & 24,369 & 12,235 & 3487 & $\mathrm{Csb}-\mathrm{Cfsb}$ & 971 \\
\hline Bueno & $39^{\circ} 54^{\prime}-41^{\circ} 17^{\prime} \mathrm{S}$ & $71^{\circ} 40^{\prime}-73^{\circ} 43^{\prime} \mathrm{W}$ & 15,366 & 4165 & 2410 & $\mathrm{Cfsb}$ & 394 \\
\hline
\end{tabular}

\section{Streamflow Data}

Streamflow in the study area is monitored at 232 streamflow gauges (SFG); however, the records present important information gaps in some cases. In this work, only gauges with more than 10 years of records were considered, i.e., 100 SFG. Figure 3A-D shows the average missing streamflow data per year between 1970 and 2016 for these 100 gauges. Additionally, Figure 3E shows the gap lengths. Note that there are three groups, short gaps lasting from 1 to 2 days (37\% of gaps), medium gaps lasting between 14 and 60 days (38\% of gaps), and long gaps lasting at least 365 days ( $4 \%$ of gaps). 

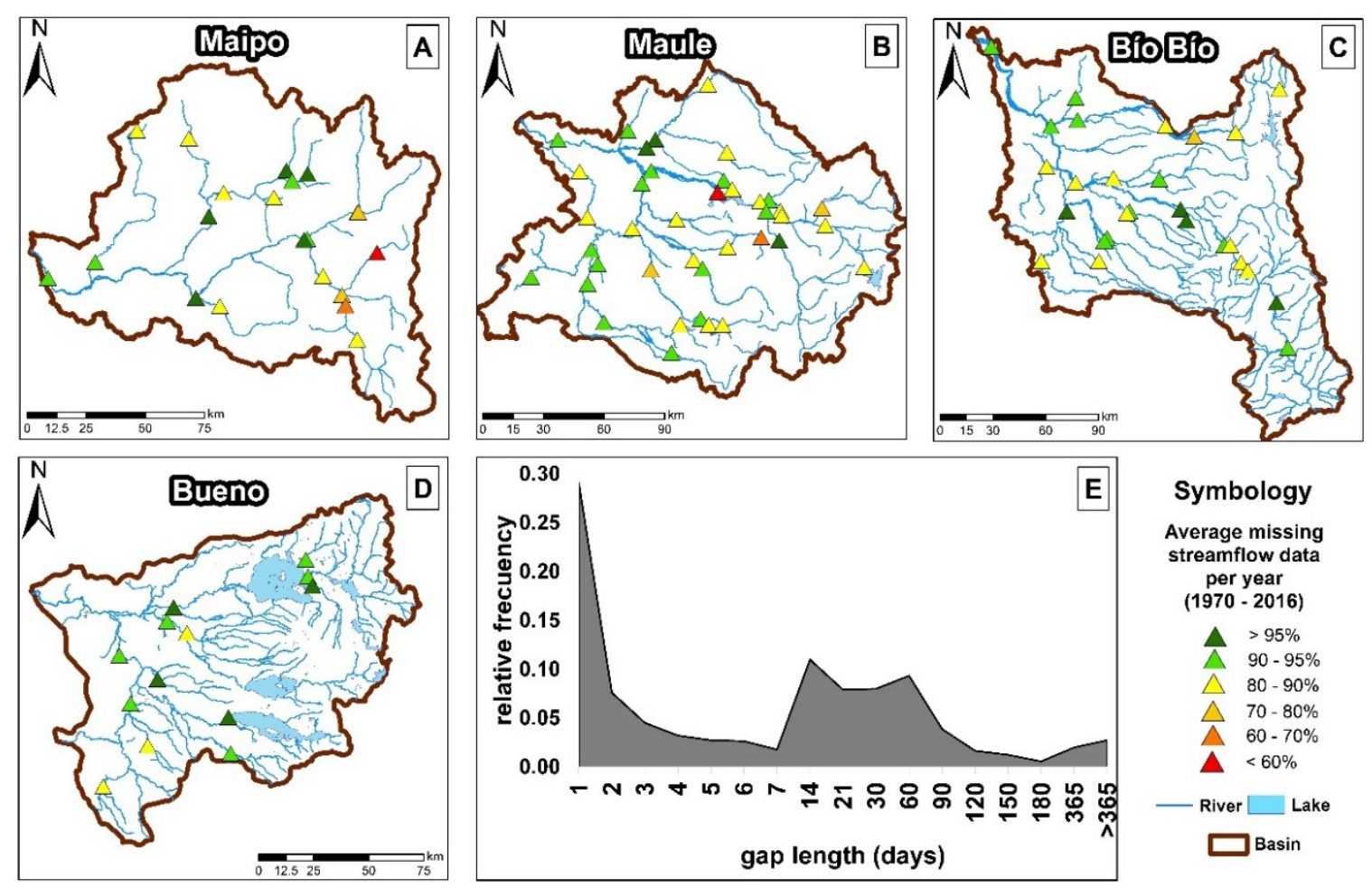

Figure 3. Available streamflow data between 1970 and 2016 in (A) Maipo, (B) Maule, (C) Bío Bío and (D) Bueno. (E) Gap lengths.

\section{Methods}

\subsection{Gap Filling Method}

As proposed by Sidibe et al. [33], streamflow data were reconstructed using the non-parametric random forest (RF) method [19] to produce a complete data set with no missing values. The method consists of predicting missing values using the RF trained on observed values. This method is particularly effective at accounting for complex interactions in non-linear datasets [20] such as streamflow data. For a given gauge $X_{i}$ in the streamflow dataset, four different groups were generated: The observed values of the variable $X_{i}\left(Y_{i}\right.$ obs $)$, the missing records of the variable $X_{i}\left(Y_{i}\right.$ miss $)$, the other variables with observed values coinciding with observation data of $X_{i}\left(X_{i}\right.$ obs $)$ and the other variables with observations coinciding with missing data of $X_{i}\left(X_{i}\right.$ miss). The initial step consists of a mean imputation of missing values. Each variable is then sorted according to the amount of missing data and ranked in increasing order. For each variable $X_{i}$, an RF is trained with response $Y_{i}$ obs and predictors $X_{i}$ obs. The relationship is then applied to $Y_{i}$ miss to predict missing values. The process is iterated until the difference $(\Delta)$ between the newly imputed dataset and the previous one increases. Then, for $N$ variables $\Delta$ was estimated by:

$$
\Delta=\frac{\sum i \in N\left(X_{\text {new }}^{i m p}-X_{\text {old }}^{i m p}\right)^{2}}{\sum i \in N\left(X_{\text {new }}^{i m p}\right)}
$$

Following Sidibe et al. [33], we used 1000 trees and a maximum number of iterations set to 100. RF daily streamflow data filling performance was tested by creating artificial gaps at a random gauge. First, we randomly deleted a different number of observed daily flows $(30,60,90,120,180$, and 365) to assess the accuracy of the algorithm at filling the short gaps (1-2 days). Second, we randomly deleted a different number of continuous observed daily flows $(7,14,21,30,60,180$, and 365) at each gauge to assess the accuracy of the algorithm at filling the medium and long gaps. In both cases, we repeated the process 400 times (100 for each basin) and compared the RF-filled series with the observed data using 
the goodness of fit indicators (GoF), coefficient of determination $\left(R^{2}\right)$ and the percent bias (PBIAS), as recommended by Moriasi et al. [34]. We also used the modified Kling-Gupta efficiency (KGE) [35] instead of the Nash Sutcliffe efficiency (NSE), as the KGE criterion ensures that the temporal dynamics (measured by the correlation coefficient), as well as the distribution of flow (measured by the bias and variability ratio), are well represented [35]. The optimal values of $R^{2}$ and KGE are one and zero in the case of $P B I A S$, the recommended values for a satisfactory performance of simulated data are $R^{2}>0.6$ and PBIAS $\pm 15 \%$ [34], and KGE $>0.5$ [33].

\subsection{Historical Hydropower Potential}

Hydropower potential in the 1970-2016 period was computed at every $1 \mathrm{~km}$ long river reach in the study basins. Figure 4 shows the flowchart for estimating the hydropower potential. A $30 \times 30 \mathrm{~m}$ resolution digital elevation model (DEM) was obtained from the Shuttle Radar Topography Mission [36]. A virtual streamflow network (VN) similar to the actual river networks obtained from the General Water Directorate of Chile [29] was created in each study basin. The VN was split into $1 \mathrm{~km}$ long river reaches. At each reach, we calculated the water head as the difference in the upstream and downstream elevation from the DEM.

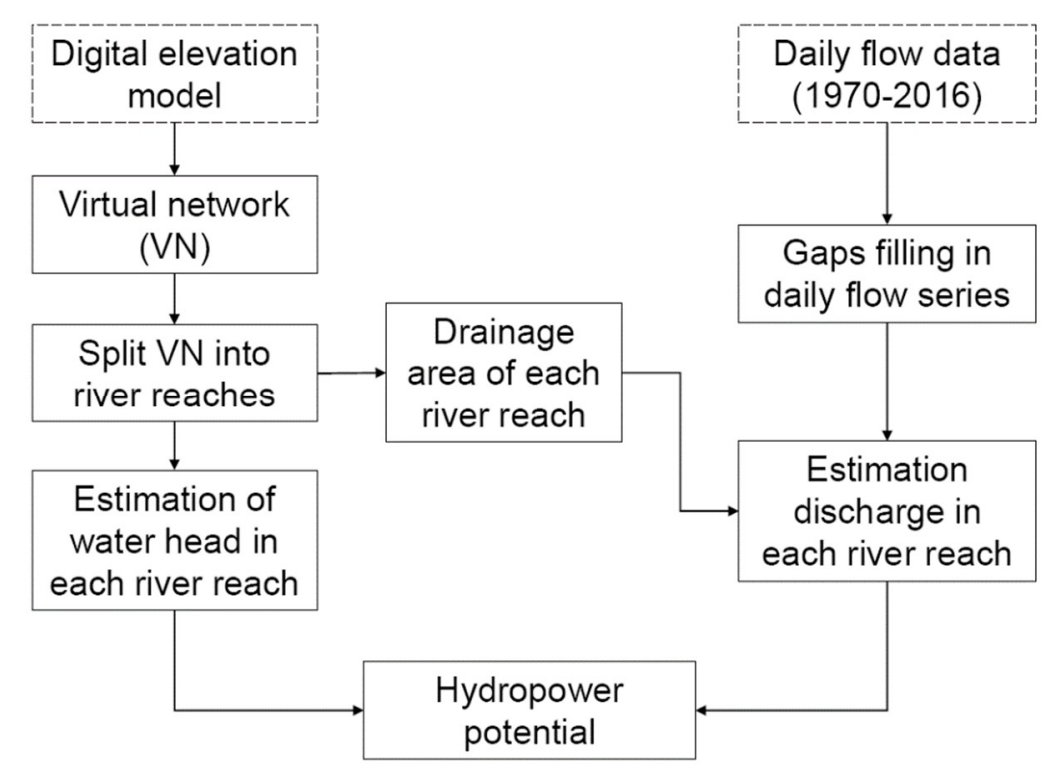

Figure 4. Flowchart for estimation of hydropower potential. Dashed lines represent the input data.

For each reach the hydropower $P$ was estimated as:

$$
P_{i, y}=\gamma Q_{30_{i, y}} H_{i}
$$

where $\gamma$ is the specific weight of water equal to $9810 \mathrm{~N} / \mathrm{m}^{3} ; Q_{30 i, y}$ is the discharge with $30 \%$ exceedance probability in the reach $i$ in the year $y ; H_{i}$ is the water head of the reach $i$. For each basin, the hydropower potential for the year $y$ was then computed as follows:

$$
P_{b a s i n, y}=\sum_{i=1}^{n} P_{i, y}
$$

where $P_{b a s i n, y}$ is the hydropower potential in the basin for the year $y$, while $n$ is the number of reaches in each basin. Reaches presenting less than $100 \mathrm{~kW}$ were deemed to be without exploitable energy [27]. Additionally, we include a supplementary Figure S1 with the effect of this criterion in the annual hydropower potential in each basin. 
Estimation of Discharge in Each River Reach

Discharges with a $30 \%$ exceedance probability were calculated for each year at each SFG using the filled daily flow series and were then interpolated for every $1 \mathrm{~km}$ reach of the $\mathrm{VN}$, transposing those of the nearest SFG by contributing area [18]:

$$
Q_{30_{i, y}}=Q_{30_{S F G}, y} \frac{A_{i}}{A_{S F G_{n}}}
$$

where $Q_{30 S F G n, y}$ is the $Q_{30}$ in the SFG $n$ for the year $y, A_{i}$ is the drainage area of the reach $i, A_{S F G n}$ is the drainage area of the SFG $n$ and $Q_{30 i, y}$ is the discharge at reach $i$ for the year $y$. The $Q_{30}$ is the typical and recommended flow select for design hydropower plants $[37,38]$.

\subsection{Trends in Hydropower Potential}

Trends in hydropower potential between 1970 and 2016 were determined using the Mann-Kendall test $[39,40]$. This test is widely used to detect trends in hydrological series, as it is a powerful tool for detecting monotonic trends [41]. As the statistical significance of the Mann-Kendall test is strongly sensitive to serial correlations [42], a variant accounting for serial correlation, which was developed by Yue [43], was used. Additionally, to evaluate the significance of the trends, we used the normalized test statistic $Z$ [44] and $p$-value. In addition, for confidence levels of $99 \%, 95 \%$, and $90 \%$, the null hypothesis of no trend is rejected if $Z>2.575,1.960$ and 1.645, respectively [44].

The magnitude of the historical hydropower potential trend was estimated through Sen's slope [45], as this approach is less sensitive to outliers and therefore provides a better estimate of slope for skewed data compared to regression methods, giving a robust estimation of the trend [41]. In addition, multi-temporal trend analysis was implemented [46,47]. This approach consists of calculating the trend for all possible segments (with a minimum length of 8 years) in the study period. For each time series, the multi-temporal trend analysis generates a diagram in which each possible pair of start and end dates is associated with a trend value.

\subsection{Correlation between Hydropower Potential and Long-Term Climate Variability}

Interpretations of global correlation patterns between hydropower potential and large-scale climate variability were first examined using four climate indices: PDO [48], NINO 3.4 [49], SAM [50], and AMO [51]. These indices were correlated with hydropower potential between 1970 and 2016. Relationships between hydropower and large-scale climate variability were then more objectively investigated through global SST. SST data sets from the extended reconstructed SST version 5 (ERSST.v5) from the National Climatic Data Center (NCDC) were used. At each grid point of the ERSST.v5 data sets from 1970 to 2016, Pearson's product moment correlation coefficients between SST and hydropower potential were computed. An ERSST.v5 gridded data set was generated using in situ data from the Comprehensive Ocean-Atmosphere Data Set (COADS) release 3, which employs new bias adjustments, quality control procedures and analysis methods, allowing for a reconstruction of sparse data over a $2^{\circ} \times 2^{\circ}$ resolution grid $[52,53]$.

\subsection{Developing Future Scenarios for Hydropower Potential Amid Climate Change}

Building upon the significant teleconnections between SST and hydroclimatic variability, we provide a novel approach to assess the impact of climate change on hydropower potentials in Chile. Future hydropower potential scenarios in the four study basins were developed based on large-scale climate variability using 15 GCMs [54] for the 1970-2050 period. Historical runs and projection simulations forced with a representative concentration pathway, RCP 4.5 [55], were used. These long-term integrations are initiated from multi-century preindustrial control integration [54], and are consistent with a midrange mitigation emissions scenario. The GCMs used in this study are listed in Table 2. The set of GCMs includes models with different spatial resolutions and degrees of 
complexity. However, in our study all ocean grids have been remapped on a regular $2^{\circ} \times 2^{\circ}$ resolution grid using bilinear interpolation (i.e., the same resolution as ERSSTv.5). In addition, to account for the contribution of internal climate variability, we used all individual members (Real Nb. in Table 2), i.e., a total of 45 simulations.

Empirical statistical downscaling models were built in the following steps. First, the long-term mean for each data set (i.e., ERSSTv.5,1970-2016, and GCMs, 1970-2050) was subtracted from that data at each grid point, and two data sets were then combined along the time axis to form a single data set covering the 1970-2050 period [56,57]. Second, a standard empirical orthogonal function (EOF) analysis [58] was applied to the anomalies of the combined data set with the common grid. The eigenvectors from the EOF analysis represent patterns of variability common to both ERSST.v5 and GCMs. The EOF analysis applied to the combined dataset was referred to as the common EOF analysis [56,57]. Third, using a stepwise screening process based on the Akaike information criterion (AIC) [59], a multiple linear regression analysis between the predictand (i.e., observed hydropower potential) and the principal components (PCs) of the 20 leading EOFs of the combined data set (ERSST.v5 + GCMs) was performed to decide the number of PCs to include as predictors in the final models. During stepwise screening, a model that minimizes loss of information in simulating historical hydropower potential (i.e., with a minimum AIC value) was retained for the downscaling process. A leave-one-out cross-validation was then performed to assess the prediction skill of the models. The leading 20 EOFs were used to allow the use of more regional detail in predictor fields in the downscaling models. Before model calibration, the best-fit linear trend was subtracted from each grid point in the observed predictor values (ERSST.v5) and from the predictand (hydropower estimations), as the presence of a linear trend may introduce systematic biases to the model calibration [60]. The downscaling models were calibrated with the part of the combined PCs that represents the actual observations (i.e. ERSST.v5), and for future projections, the downscaling was generated using part of the combined PCs that represents the GCM simulations.

Table 2. Summarized information on CMIP5 models used in the study.

\begin{tabular}{|c|c|c|c|c|c|}
\hline & Institution & Name & Real Nb. & Variable & Hist. Period \\
\hline \multirow{10}{*}{ 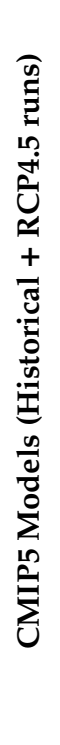 } & BCC, China & $\begin{array}{c}\text { bcc-csm1-1 } \\
\text { bcc-csm1-1-m }\end{array}$ & $\begin{array}{l}1 \\
1\end{array}$ & SST & 1970-2050 \\
\hline & CCCma, Canada & CanESM2 & 5 & SST & 1970-2050 \\
\hline & CMCC, Italy & $\begin{array}{l}\text { CMCC-CM } \\
\text { CMCC-CMS }\end{array}$ & $\begin{array}{l}1 \\
1\end{array}$ & SST & 1970-2050 \\
\hline & CNRM, France & CNRM-CM5 & 1 & SST & 1970-2050 \\
\hline & CSIRO-BOM, Australia & $\begin{array}{l}\text { ACCESS1-0 } \\
\text { ACCESS1-3 }\end{array}$ & $\begin{array}{l}1 \\
1\end{array}$ & SST & 1970-2050 \\
\hline & CSIRO-QCCCE, Australia & CSIRO-Mk3-6-0 & 10 & SST & 1970-2050 \\
\hline & NASA-GISS, USA & $\begin{array}{l}\text { GISS-E2-H } \\
\text { GISS-E2-R }\end{array}$ & $\begin{array}{l}6 \\
6\end{array}$ & SST & 1970-2050 \\
\hline & NCAR, USA & CCSM4 & 6 & SST & 1970-2050 \\
\hline & NOAA-GFDL, USA & $\begin{array}{c}\text { GFDL-CM3 } \\
\text { GFDL-ESM2M }\end{array}$ & $\begin{array}{l}3 \\
1\end{array}$ & SST & $\begin{array}{l}1970-2050 \\
1970-2050\end{array}$ \\
\hline & NSF-DOE-NCAR, USA & CESM1-BCG & 1 & SST & 1970-2050 \\
\hline
\end{tabular}

\section{Results and Discussion}

\subsection{Gap-Filling Perfomance}

Figure 5 shows the validation results of the RF method of filling gaps, as determined through $\mathrm{R}^{2}$, PBIAS, and KGE. Regarding random gaps (left column), all boxes are over the recommended value for 
$\mathrm{R}^{2}$ and KGE and are within the recommended values for PBIAS, suggesting a satisfactory performance at least $75 \%$ of the times the gaps were filled; thus, RF presented good gap-filling performance. Regarding continuous gaps (right column), different behaviors are observed regarding the filling of medium and long gaps using RF. For long gaps, the three indicators are over the recommended values (within the recommended values for PBIAS), suggesting that RF is good at filling long gaps ( $>365$ days). In the case of medium gaps, RF performs worse, but $R^{2}$ the median is above the recommended value, indicating good performance at least $50 \%$ of the time. The PBIAS are also within the recommended values, except in the first percentile for gaps with lengths of 60 and 180 days, which means that RF tends to slightly overestimate the value of the daily flow in these cases. In addition, the most scattered results occurred for medium gaps according to PBIAS. Finally for KGE, the median is above the recommended value, except for 7 -day gaps, indicating that at least $50 \%$ of the time RF performs well. Therefore, RF performs well at filling short and long gaps, but presents some deficiencies regarding the filling of medium gaps, tending to slightly overestimate the daily flow and have some difficulty filling the 7-day gaps. Furthermore, as our streamflow data were dominated by short and long gaps, and medium gaps longer than 14 days (Figure 4), and in agreement with Moriasi et al. [34] and Sidibe et al. [33], the results suggest that the RF method has a good gap-filling performance.
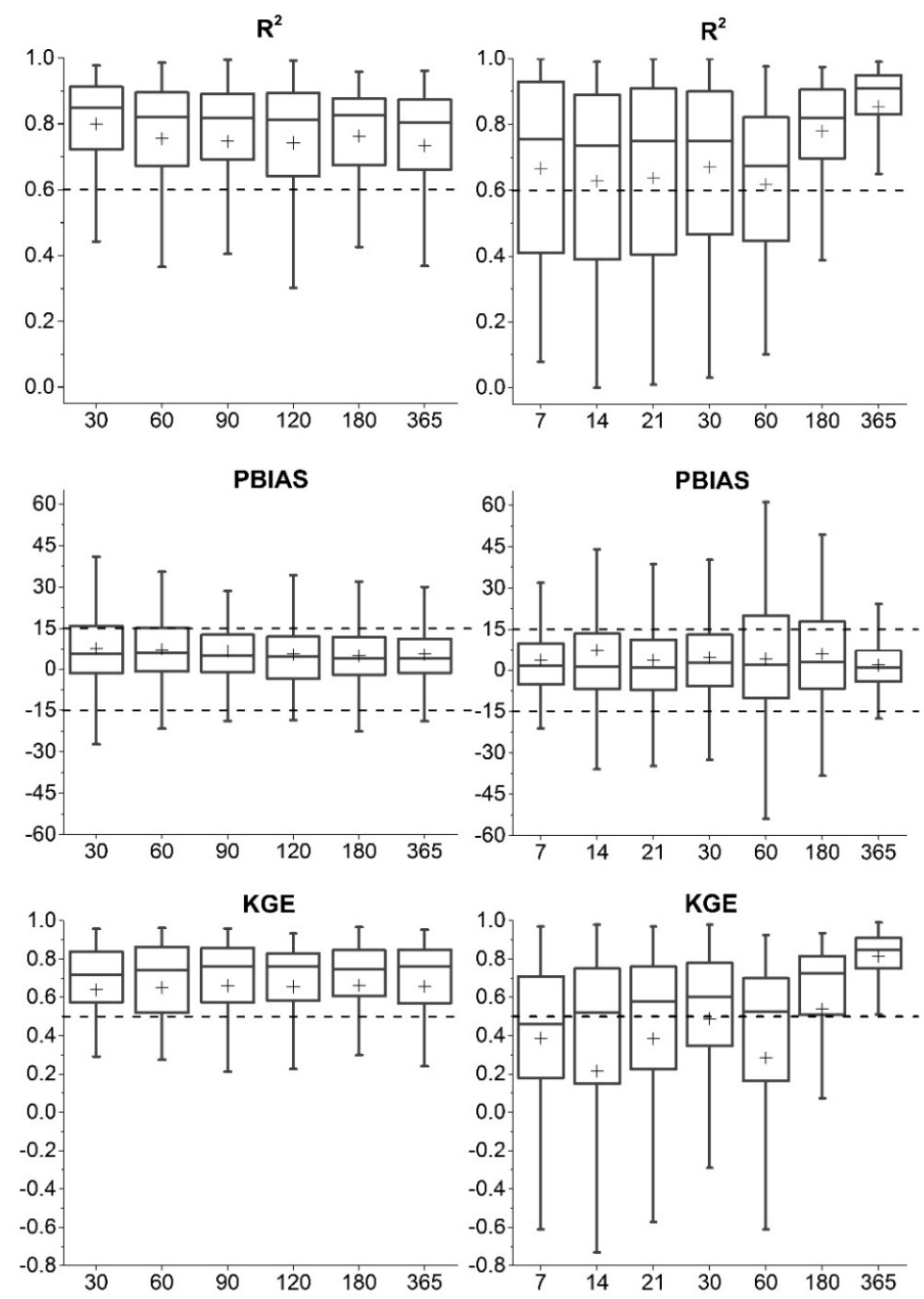

Figure 5. Validation of the RF method of filling the gaps in daily flow series, as determined through $R^{2}$, percent bias (PBIAS), and Kling-Gupta efficiency (KGE). The left column shows the results for the random gaps and the right column shows the results for random continuous gaps. The crosses indicate the mean value and the dashed lines represent the recommend value. 


\subsection{Hydropower Potential Variability and Trends}

Figure 6 shows the time evolution of hydropower potential, and corresponding boxplots illustrating the variability, between 1970 and 2016 in the four study basins. Substantial variations and inter-basin differences are detected in all basins (Figure 6). For instance, in 1997, the Maule, Bío Bío and Bueno basins presented a high hydropower potential $(7.15,8.71$ and $4.40 \mathrm{GW}$, respectively), which drastically decreased in 1998 (2.58, 2.59, and $1.84 \mathrm{GW}$, respectively). A similar behavior was identified in Maipo, but in different years (Figure 6): in 1986, the potential was 2.89 GW, increasing to $4.85 \mathrm{GW}$ in 1987 . As evidenced by the boxplots, the greatest variability is identified in the Bío Bío and Maule basins, with maximum differences of 8.23 and $6.29 \mathrm{GW}$, respectively (Figure 6). In addition, all basins show a decreasing trend from 1970 to 2016 (Figure 6). This is confirmed in Figure 7, which summarizes the statistics of the Mann-Kendall trend tests. The $S$ statistics show decreasing trends in all basins. $\mathrm{Z}$ and $p$ values show that the identified trends are significant at the $95 \%$ confidence level. A less pronounced trend is found in Bío Bío (Figure 7), and could reflect the climate transition zone defined by Muñoz et al. [61]. Sen's slope shows maximum decreasing rates between -47 and $-45 \mathrm{MW} / \mathrm{year}$ in Bío Bío and Maule, respectively (Figure 7), where the highest hydropower potential variability was found (Figure 6). The smallest decreasing rates are observed in Maipo and Bueno (-23 and $-22 \mathrm{MW} / \mathrm{year}$, respectively; Figure 7), where the smallest hydropower potential variability was found (Figure 6). These results were consistent with reported precipitation $[62,63]$ and river discharge trends $[64,65]$.
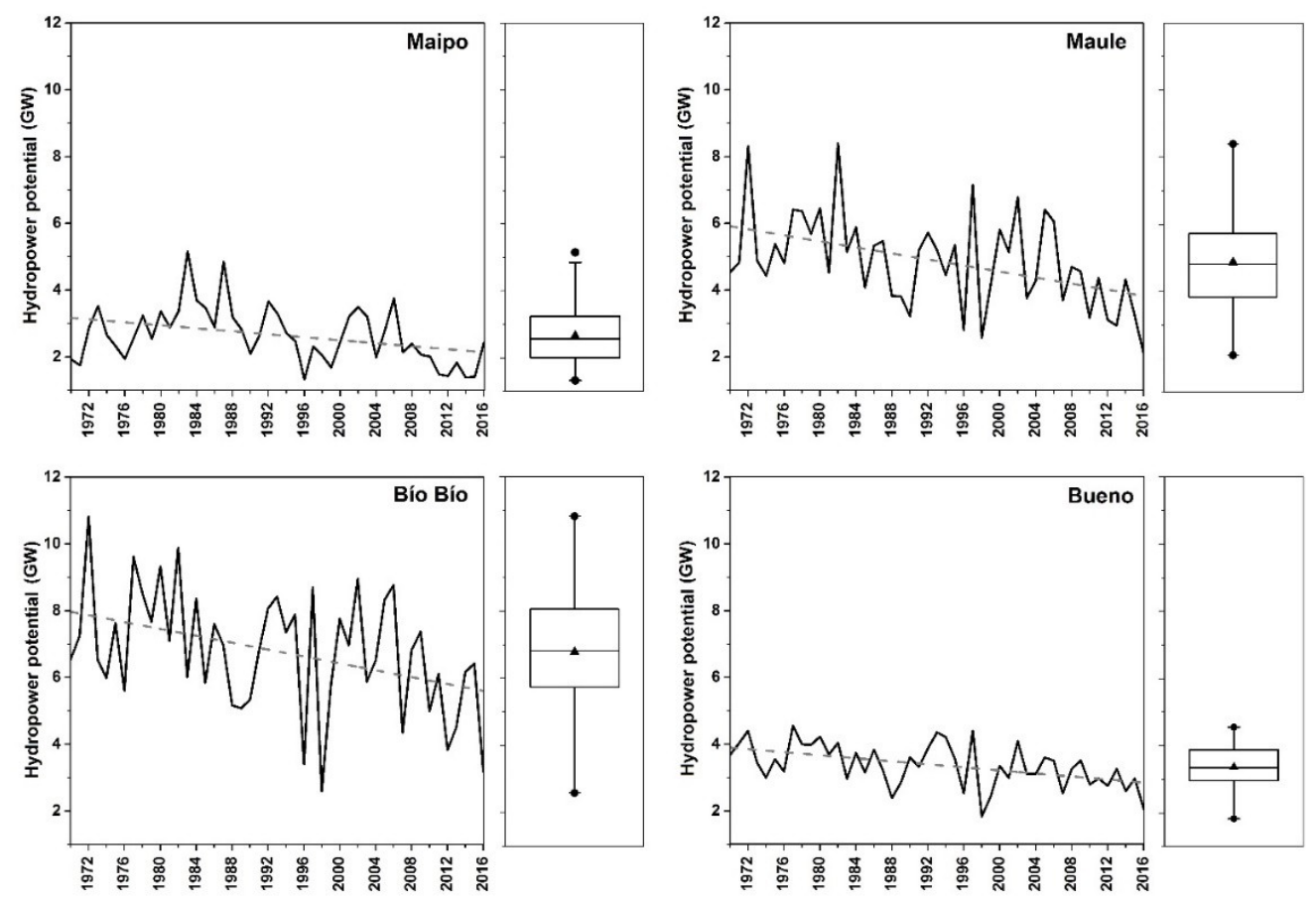

Figure 6. Time evolution of hydropower potential, and corresponding boxplots, between 1970 and 2016 in the four study basins. Dashed lines represent the trend. In the box plots, black circles show the maximum and minimum values, while the black triangle represents the mean value. 

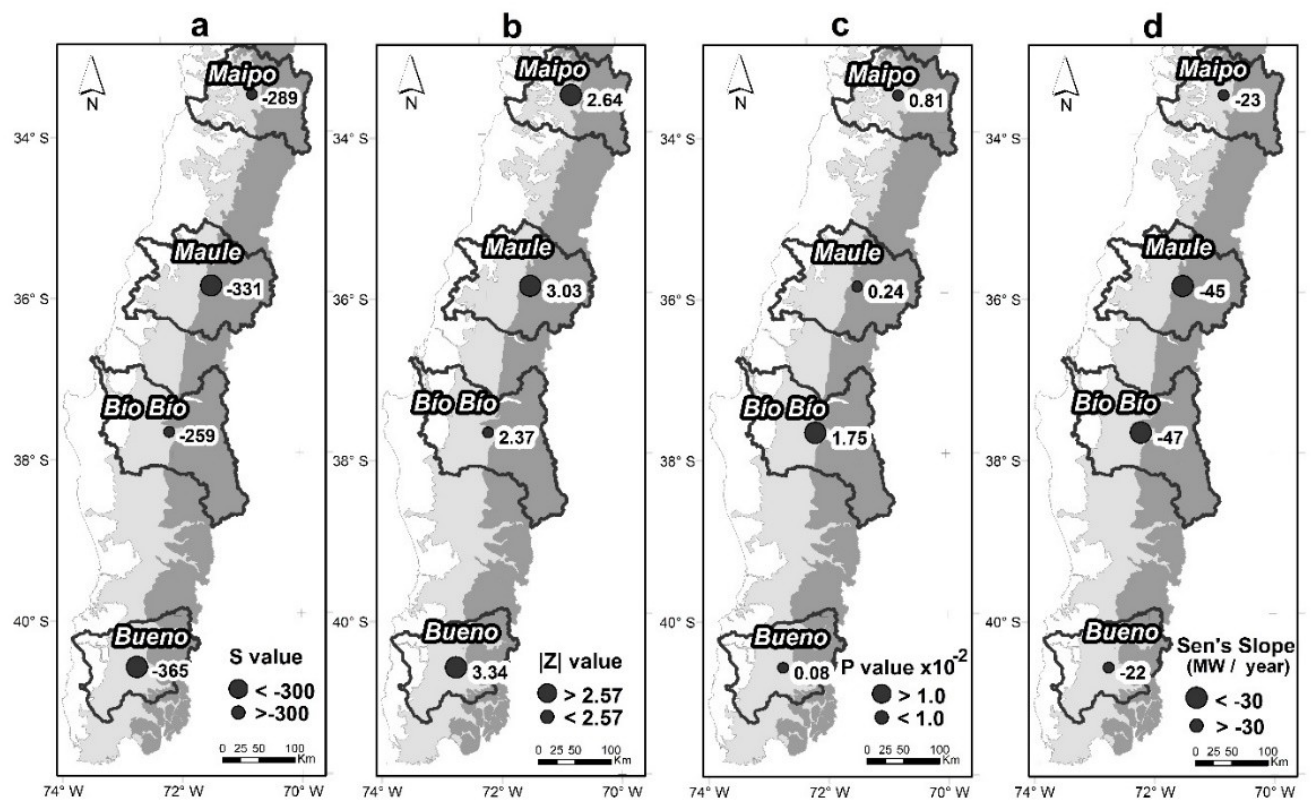

Figure 7. Hydropower trends in the four study basins. $S$ value (a), $Z$ values (b), $p$-values (c), and Sen's slope (d).

The relative importance of variability and trends in hydropower between 1970 and 2016 is analyzed using multi-temporal trend analysis in Figure 8.
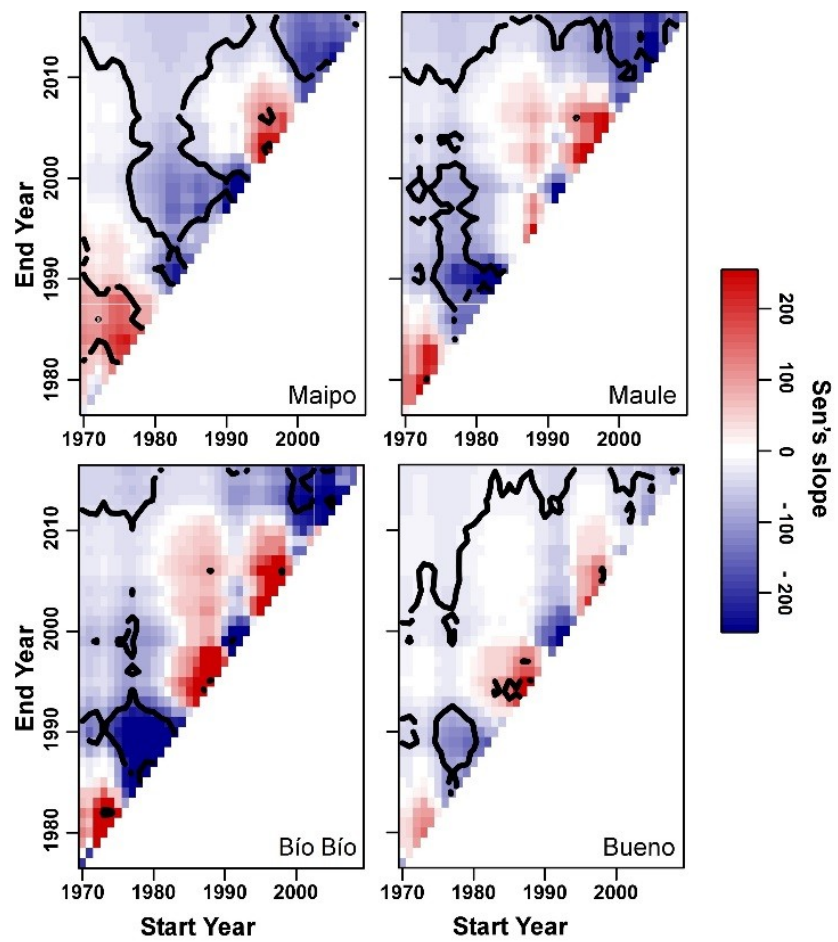

Figure 8. Multi-temporal trend diagrams for hydropower potential between 1970 and 2016 in the four study basins. Trends in MW are presented in red (positive), white (null) and blue (negative). Contour lines indicate the statistical significance at the 95\% confidence level $(p=0.05)$.

Significant decreasing trends, at the $95 \%$ confidence level, are identified in all basins for periods greater than 40 years (upper left corner in each graph in Figure 8), consistent with the results obtained in Figure 7. Additionally, blue, i.e., decreasing trends, is more frequent than red, especially in the recent 
period (2000 onward) in all the basins (Figure 8). Furthermore, alternating positive and negative trends, modulating the general trend, are observed in all basins over periods shorter than 20 years (Figure 8 ). These modulations show stronger magnitude than the general trend. For instance, the general trend in Maipo over the entire period was $-23 \mathrm{MW} \cdot \mathrm{year}^{-1}$ (Figure 7), but increasing and decreasing trends greater than $100 \mathrm{MW} \cdot \mathrm{year}^{-1}$ were observed between 1970 to 1980 and 1980 to 1990, respectively (Figure 8). Similar results are found in Maule, Bío Bío, and Bueno, but in slightly different periods (Figure 8), suggesting different regional patterns. For instance, between 1970 and 1980, a significant $(p=0.05)$ increasing trend was found only in Maipo (Figure 8), while the other basins present a weak increasing trend (Maule and Bío Bío) or no trend (Bueno), and in 1976, a significant decreasing trend begins (Maule, Bío Bío, and Bueno), contrary to the increasing trend in Maipo.

These results highlight interannual to decadal modulations in hydropower potential in Chile, which are related to large-scale climate controls. In addition, regional patterns in hydropower variability were identified.

\subsection{Correlation between Hydropower Potential and Long-Term Climate Variability}

Figure 9 shows the correlation between hydropower potential and climate indices in the study basins.
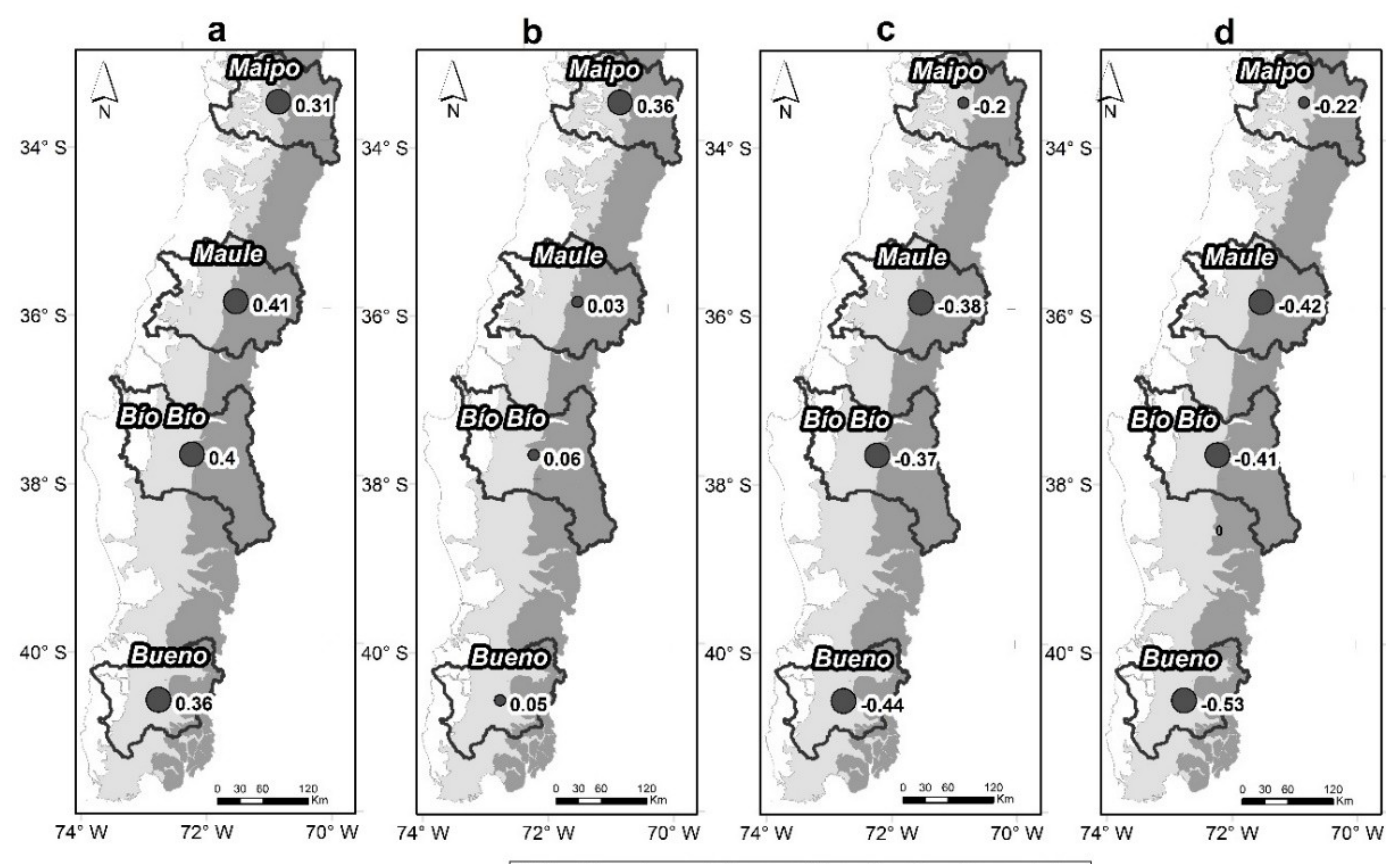

Significant correlation $\bullet$ Non-significant correlation

Figure 9. Correlation between hydropower potential and ENSO (a), PDO (b), SAM (c), and AMO (d) in the study basins.

Significant correlations between the Nino 3.4 index and hydropower were detected (Figure 9). This relationship is consistent with results from previous studies $[63,64,66]$, which describe a strong ENSO impact on rainfall and streamflow variability in Chile. Significant correlations between the PDO index and hydropower potential, at a 95\% confidence level, were detected only in Maipo (Figure 9), consistent with the regional patterns identified in Figures 6 and 8. This is also consistent with the findings of Valdés-Pineda et al. [67] and suggests important contributions of decadal climate fluctuations to hydropower potential in the Northernmost basin. The correlation between hydropower potential and the AMO index indicates an influence of Atlantic SST on hydropower potential in the southern basins (Figure 9), consistent with the findings of Valdés-Pineda et al. [67]. Similarly, 
the correlation between hydropower potential and the SAM index indicates an influence of Antarctic oscillation on hydropower potential in the Southern basins (Figure 9).

Figure 10 shows pointwise correlations between global SSTs and hydropower potential between 1970 and 2016. Hydropower potential in all basins between 1970 and 2016 is significantly correlated, at a 95\% confidence level, with SST anomalies in the Pacific Ocean (Figure 10): Positive correlations in the tropical Pacific flanked by a horseshoe pattern of the opposite sign. This correlation pattern highlights the strong relationship between hydropower potential and ENSO in Chile. Some regional differences, however, emerge in the relationship between hydropower potential and global SSTs. Maipo is significantly negatively correlated with SST anomalies in the northern North Pacific, while there is no significant correlation in the Southern basins (i.e., Maule, Bío Bío, and Bueno), confirming the influence of the PDO observed in Figure 9. At the same time, hydropower potential in southern basins (Maule, Bío Bío and Bueno) shows significant correlations with SST anomalies in the North to equatorial Atlantic (Figure 10), confirming the influence of the AMO observed in Figure 9. Hydropower potential in the basins South of Maule is significantly correlated with dipolar SST anomalies in the Southeast Pacific off the Chilean coast (Figure 10). This South Pacific dipolar SST anomaly could be associated with Southward shifts of the mid-latitude westerlies, leading to colder than normal SSTs in the South and warmer than normal SST in the North of westerlies climatological location. This last result is consistent with the significant correlation between hydropower potential in the basins south of Maule and the SAM index, highlighting a greater sensitivity to regional changes in the mid-latitude westerlies in this region in accordance with Gillet et al. [68] and Quintana and Aceituno [62].

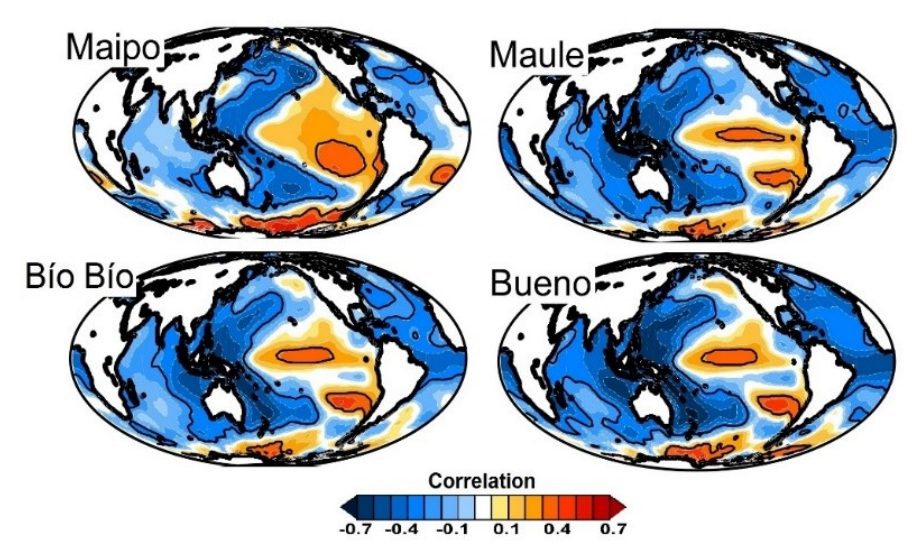

Figure 10. Pointwise correlations between hydropower and global SSTs between 1970 and 2016. Black contours indicate statistical significance at $p=0.05$ according to the Pearson's product moment correlation coefficient.

In summary, hydropower potential in the four studied basins is primarily related to ENSO, with correlations greater than 0.65 in central Pacific, Figure 10. However, some regional differences appear in the relationships between large-scale climate variability and hydropower potential. For instance, hydropower potential in the basins South of Maule is also strongly related to SST anomalies in the Atlantic Ocean and appears very sensitive to changes in the mid-latitude westerlies. This suggests that a global domain is preferable to different regional domains (e.g., equatorial Pacific, North and South Pacific, and North Atlantic) when developing the future scenarios based on the relationship with large-scale climate variability.

\subsection{Future Scenarios for Hydropower Amid Climate Change}

Figure 11 shows the hydropower potential and installed hydropower capacity in the four study basins in the 1970-2050 period. The prediction skill of the models is summarized by the Pearson's correlation values between calibration and validation data. 

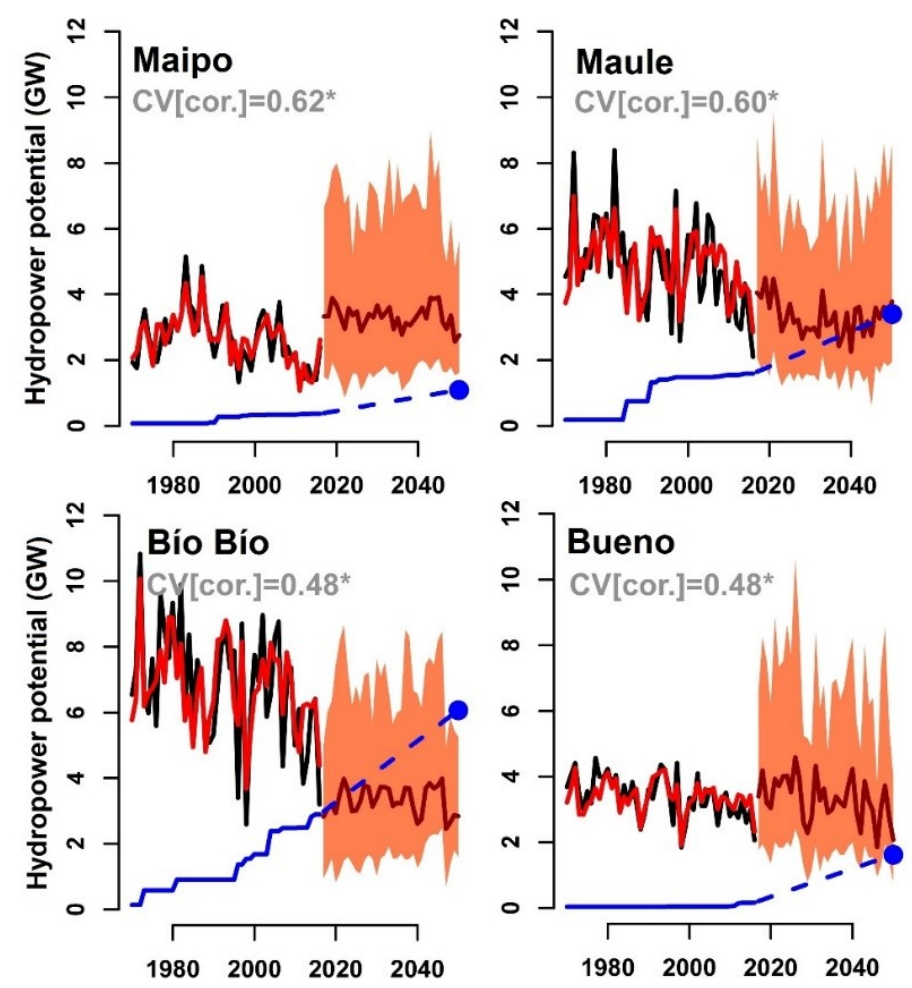

Figure 11. Hydropower potential and installed hydropower capacity in the four study basins in the 1970-2050 period. Black lines show observed hydropower potential. Red lines indicate computed hydropower over the calibration period. Dark red lines and associated coral polygons display the mean, max and min projected hydropower potential using all simulations from 15 GCMs (i.e., 45 simulations). Installed hydropower capacity is displayed as blue lines, while blue dots indicate projected installed hydropower capacity $[25,27]$. Results of the leave-one-out cross-validation are shown in grey.

The model skills were generally stronger in Maipo and Maule than in Bío Bío and Bueno (Figure 11). As also highlighted in Figure 8, Northern basins showed more pronounced low-frequency variability and trends, which enhance predictability for the Northern basins. Overall, the correlation coefficients between calibration and validation data are significant at $p=0.05$, and range between 0.48 and 0.62 (Figure 11), suggesting moderate to good prediction skills. Statistical downscaling models performed well at simulating historical hydropower potential (1970-2016) in all basins. Observed discrepancies between the hydropower potential predictions of the different models could arise from discrepancies between the different GCMs, as well as between simulations of the same model, when computing future global SST variability (IPCC 2014). For instance, the future trends of ENSO, which is an important driver of hydro-climatic variability in Chile, are heavily model-dependent and generally within the range of natural variations [69].

Table 3 shows the average change in hydropower potential between the historic period and the projections obtained for the four study basins. The mean and median projected hydropower potential (2017-2050) remain in the same range as observed hydropower potential (1970-2016), suggesting high hydropower availability during the next 30 years. Nevertheless, the extreme values (minimum and maximum) present the greatest expected variations: the minimum values in Maipo, Maule and Bío Bío decrease by $40.4 \%, 30.9 \%$, and $13.9 \%$, respectively; the maximum value decreases by $6.1 \%$ in Maipo, while it increases by $7.9 \%$ and $8.2 \%$ in Bío Bío and Bueno. In addition, Table 4 shows the results of the hydropower trend analysis of the future period, i.e., $S, Z$, and $p$-values statistics, as well as Sen's slope. Projected hydropower presents decreasing trends in Maipo, Bío Bío, and Bueno at rates of $-43,-25$, and $-40 \mathrm{MW} /$ year, respectively (Table 4). Meanwhile, no projected hydropower potential trends are detected in Maule, in contrast with the decreasing trend observed in the past. 
Table 3. Average projected change in hydropower potential in the four study basins.

\begin{tabular}{|c|c|c|c|c|}
\hline \multicolumn{5}{|c|}{ Hydropower Potential (GW) } \\
\hline Basin & Statistic & Historic (1970-2016) & Future (2017-2050) & Change (\%) \\
\hline \multirow{6}{*}{ Maipo } & Max. & 5.15 & 4.84 & $-6.1 \%$ \\
\hline & $75 \%$ & 3.23 & 3.21 & $-0.4 \%$ \\
\hline & $50 \%$ & 2.58 & 2.64 & $2.3 \%$ \\
\hline & $25 \%$ & 2.03 & 2.10 & $3.4 \%$ \\
\hline & Min. & 1.33 & 0.79 & $-40.4 \%$ \\
\hline & Mean & 2.66 & 2.67 & $0.5 \%$ \\
\hline \multirow{6}{*}{ Maule } & Max. & 8.39 & 8.54 & $1.8 \%$ \\
\hline & $75 \%$ & 5.71 & 5.77 & $1.1 \%$ \\
\hline & $50 \%$ & 4.81 & 4.88 & $1.3 \%$ \\
\hline & $25 \%$ & 3.95 & 3.96 & $0.2 \%$ \\
\hline & Min. & 2.10 & 1.45 & $-30.9 \%$ \\
\hline & Mean & 4.87 & 4.87 & $0.0 \%$ \\
\hline \multirow{6}{*}{ Bío Bío } & Max. & 10.82 & 11.68 & $7.9 \%$ \\
\hline & $75 \%$ & 7.97 & 7.99 & $0.2 \%$ \\
\hline & $50 \%$ & 6.82 & 6.79 & $-0.5 \%$ \\
\hline & $25 \%$ & 5.79 & 5.54 & $-4.3 \%$ \\
\hline & Min. & 2.59 & 2.23 & $-13.9 \%$ \\
\hline & Mean & 6.78 & 6.79 & $0.1 \%$ \\
\hline \multirow{6}{*}{ Bueno } & Max. & 4.56 & 4.93 & $8.2 \%$ \\
\hline & $75 \%$ & 3.86 & 3.78 & $-2.1 \%$ \\
\hline & $50 \%$ & 3.35 & 3.36 & $0.2 \%$ \\
\hline & $25 \%$ & 2.97 & 2.96 & $-0.4 \%$ \\
\hline & Min. & 1.84 & 1.87 & $2.1 \%$ \\
\hline & Mean & 3.37 & 3.37 & $0.0 \%$ \\
\hline
\end{tabular}

Table 4. Trend analysis of future period (2017-2050).

\begin{tabular}{ccccc}
\hline Statistic & Maipo & Maule & Bío Bío & Bueno \\
\hline$S$ & -475 & -73 & -309 & -503 \\
\hline$Z$ & 4.78 & 0.73 & 3.09 & 5.09 \\
\hline$p$-value & 0.00006 & 0.456 & 0.0019 & 0.00008 \\
\hline Sen's Slope (MW/year) & -43 & No Trend & -25 & -40 \\
\hline
\end{tabular}

The future hydropower scenarios show high hydropower availability in the four study basins; however, the expected hydropower development should be reviewed, as Maule and Bío Bío exhibit more installed hydropower capacity than hydropower potential by 2050 (blue line, Figure 11), which means a significant risk of overinvestment in hydropower plants in these two basins. By contrast, in Maipo and Bueno, hydropower development would not exploit the all available resources by 2050. These results highlight the importance of considering climate variability when planning hydropower development at the basin scale; thus, for example, in Bío Bío projected hydropower developments should be reviewed to mitigate the risk of overinvestment, as the observed decreasing hydropower potential trends are very likely to persist over the next 30 years (Figure 11, Table 4) and could potentially lead to overinvestment in the very near term. In addition, expected climate change effects lead to decreases in the minimum values (Table 3), which means the lows flows in future will be smaller; therefore, reviewing turbine sizes in hydropower projects may be necessary, i.e., decreasing the power of the turbines or installing several small units to avoid inefficient use of hydropower resources. 


\section{Conclusions}

The impacts of climate change on hydropower potential in a data-scarce region dominated by different climatic oscillations were analyzed by linking observed hydropower potential with the long-term climate variability, represented here by SST, in four basins of central Chile. This method of developing future scenarios is a good alternative to apply in regions where it is difficult to calibrate hydrological models, where clear links between hydropower and climate variability can be found, as is the case in the four study basins and in many regions of the world.

Decreasing trends in hydropower potential between 1970 and 2016, were found in all study basins at rates between -22 to $-47 \mathrm{MW} \cdot \mathrm{year}^{-1}$. The multi-temporal trend analysis showed modulations in the general trends, i.e., alternating positive and negative trends on a decadal scale. Contributions of these decadal modulations proved to be even more important than the general trends, and therefore, of crucial importance for hydropower resource management. To identify drivers of the controlling decadal modulations in hydropower potential in Chile, potential linkages with large-scale climate variability were investigated. In all basins, hydropower potential was primarily correlated with ENSO, highlighting a strong dependence on tropical climate variability. In particular, the impact of ENSO on hydropower potential was shown to be regionally modulated by other modes of climate variability. In the northernmost basin (i.e., Maipo), hydropower potential was significantly correlated with the PDO, which means that the higher (or lower) availability of hydropower occurs during the positive (or negative) phases of the PDO. In the southern basins (i.e., Maule, Bío Bío, and Bueno) hydropower potential was significantly negatively correlated with the SAM and AMO, highlighting a greater sensitivity to changes in the mid-latitude westerlies in this region. This means that there is higher hydropower availability in the negative phases of the SAM and AMO and lower availability in the positive phases. Therefore, it is concluded that availability of the hydroelectric resources is substantially modulated by large-scale climate fluctuations.

On the one hand, the future scenarios show high unexploited and thus available hydropower resources in the four study basins over the next 30 years. On the other hand, the scenarios show that the main effects of climate change on hydropower potential will be reflected in extreme values, especially minimums; e.g., in Maipo it is expected that minimum hydropower potential values will decrease by $40.4 \%$ respect to the present. In addition, these scenarios showed that hydropower development needs to consider the specific climate variability in a basin to optimize the energy generation minimizing the negative impacts, e.g., the expect installed hydropower capacity by 2050 in Maule and Bío Bío will reach a condition close to overinvestment in hydropower plants, while in Maipo and Bueno hydropower resources will remain nearly unexploited in 2050.

Finally, the results of this research show the need to generate policies that not only promote hydropower development in an area, e.g., the NCRE policy issued in 2008 in Chile, but also consider variability in hydropower resources and impacts of climate variability and change, especially in regions where massive investments in hydropower are planned, so as to achieve an optimal use and sustainable development of hydropower resources.

Supplementary Materials: The following are available online at http://www.mdpi.com/1996-1073/12/14/2747/s1, Figure S1: Effect of minimum power criterion on the annual hydropower potential in each basin.

Author Contributions: All authors contributed extensively of the work of this paper. Conceptualization, O.L. and P.A.; methodology, P.A., B.D. and M.S.; validation, P.A. and B.D.; writing-original draft preparation, P.A. and B.D.; writing-review and editing, O.L.

Funding: This research received no external funding.

Acknowledgments: The authors thank the Energy Doctorate Program of the Universidad de Concepción for providing the institutional support to conduct this research and Martin Wilkes for his help in building the interdisciplinary team that conducted this study.

Conflicts of Interest: The authors declare no conflict of interest. 


\section{References}

1. International Energy Agency. Energy Statistics; International Energy Agency: Paris, France, 2018.

2. Barros, R.M.; Tiago Filho, G.L. Small hydropower and carbon credits revenue for an SHP project in national isolated and interconnected systems in Brazil. Renew. Energy 2012, 48, 27-34. [CrossRef]

3. Zarfl, C.; Lumsdon, A.E.; Tockner, K. A global boom in hydropower dam construction. Aquat. Sci. 2015, 77, 161-170. [CrossRef]

4. Killingtveit, A. Hydropower. In Managing Global Warmimng; Elsevier: Amsterdam, The Netherlands, 2019; pp. 265-315.

5. Zhou, Y.; Hejazi, M.; Smith, S.; Edmonds, J.; Li, H.; Clarke, L.; Calvin, K.; Thomson, A. A comprehensive view of global potential for hydrogenerated electricity. Energy Environ. Sci. 2015, 8, 2622-2633. [CrossRef]

6. Zhang, X.; Li, H.Y.; Deng, Z.D.; Ringler, C.; Gao, Y.; Hejazi, M.I.; Leung, L.R. Impacts of climate change, policy and Water-Energy-Food nexus on hydropower development. Renew. Energy 2018, 116, 827-834. [CrossRef]

7. Van Vliet, M.T.H.; Wiberg, D.; Leduc, S.; Riahi, K. Power-generation system vulnerability and adaptation to changes in climate and water resources. Nat. Clim. Chang. 2016, 6, 375-380. [CrossRef]

8. Engeland, K.; Borga, M.; Creutin, J.-D.; François, B.; Ramos, M.-H.; Vidal, J.-P. Space-time variability of climate variables and intermittent renewable electricity production-A review. Renew. Sustain. Energy Rev. 2017, 79, 600-617. [CrossRef]

9. Fabry, F. On the determination of scale ranges for precipitation fields. J. Geophys. Res. 1996, 101, 12819-12826. [CrossRef]

10. Garreaud, R.D.; Vuille, M.; Compagnucci, R.; Marengo, J. Present-day South American climate. Palaeogeogr. Palaeoclimatol. Palaeoecol. 2009, 281, 180-195. [CrossRef]

11. Ng, J.Y.; Turner, S.W.D.; Galelli, S. Influence of El Niño Southern Oscillation on global hydropower production. Environ. Res. Lett. 2017, 12, 034010. [CrossRef]

12. Carvajal, P.E.; Anandarajah, G.; Mulugetta, Y.; Dessens, O. Assessing uncertainty of climate change impacts on long-term hydropower generation using the CMIP5 ensemble-The case of Ecuador. Clim. Chang. 2017, 144, 611-624. [CrossRef]

13. Turner, S.W.D.; Hejazi, M.; Kim, S.H.; Clarke, L.; Edmonds, J. Climate impacts on hydropower and consequences for global electricity supply investment needs. Energy 2017, 141, 2081-2090. [CrossRef]

14. Hu, Y.; Jin, X.; Guo, Y. Big data analysis for the hydropower development potential of ASEAN-8 based on the hydropower digital planning model. J. Renew. Sustain. Energy 2018, 10, 034502. [CrossRef]

15. Hamududu, B.H.; Killingtveit, $\AA$. Hydropower production in future climate scenarios; the case for the Zambezi River. Energies 2016, 9, 502. [CrossRef]

16. Hamududu, B.H.; Killingtveit, Å. Hydropower production in future climate scenarios: The case fro Kwanza River, Angola. Energies 2016, 9, 363. [CrossRef]

17. Devia, G.K.; Ganasri, B.P.; Dwarakish, G.S. A Review on Hydrological Models. Aquat. Procedia 2015, 4, 1001-1007. [CrossRef]

18. Emerson, D.G.; Vecchia, A.V.; Dahi, A.L. Evaluation of Drainage-Area Ratio Method Used to Estimate Streamflow for the Red River of the North Basin, North Dakota and Minnesota. Scientific Investigations Report 2005-5017 Evaluation of Drainage-Area Ratio Method Used to Estimate Streamflow for th. Sci. Investig. Rep. 2005. [CrossRef]

19. Breiman, L. Random forests. Mach. Learn. 2001, 45, 5-32. [CrossRef]

20. Stekhoven, D.J.; Bühlmann, P. Missforest-Non-parametric missing value imputation for mixed-type data. Bioinformatics 2012, 28, 112-118. [CrossRef]

21. Chilkoti, V.; Bolisetti, T.; Balachandar, R. Climate change impact assessment on hydropower generation using multi-model climate ensemble. Renew. Energy 2017, 109, 510-517. [CrossRef]

22. Comision Nacional de Energía Estadísticas electricidad en Chile. Available online: https://www.cne.cl/ estadisticas/electricidad/ (accessed on 18 March 2019).

23. Pollitt, M.G. Electricity reform in Chile: Lessons for developing countries. J. Netw. Ind. 2004, 5, $221-262$. [CrossRef]

24. Infraestructura de Datos Espaciales, Ministerio de Energía de Chile. Available online: http://sig.minenergia. cl/sig-minen/moduloCartografico/composer/ (accessed on 2 January 2018). 
25. Potencial Hidroeléctrico de Chile. Available online: http://walker.dgf.uchile.cl/Explorador/DAANC/ (accessed on 2 January 2018).

26. Liang, X.; Lettenmaier, D.P.; Wood, E.F.; Burges, J. A simple hydrologically based model of land surface water and energy fluxes for general circulation models. J. Geophys. Res. 1994, 99, 14415-14428. [CrossRef]

27. Santana, C.; Falvey, M.; Ibarra, M.; García, M. Energías Renovables en Chile. El Potencial Eólico, Solar e Hidroeléctrico de Arica a Chiloé. 2014. Available online: http://www.minenergia.cl/archivos_bajar/Estudios/ Potencial_ER_en_Chile_AC.pdf (accessed on 28 January 2018).

28. Energía 2050: Política Energética de Chile. Available online: http://www.energia2050.cl/es/energia-2050/ energia-2050-politica-energetica-de-chile/ (accessed on 26 October 2017).

29. Mapoteca Digital de Chile. Available online: http://www.dga.cl/estudiospublicaciones/mapoteca/Paginas/ default.aspx (accessed on 2 January 2018).

30. Rioseco, R.; Tesser, C. Cartografía Interactiva de Los Climas de Chile. Available online: http://www7.uc.cl/ sw_educ/geografia/cartografiainteractiva/index.htm (accessed on 15 January 2018).

31. Centro de Ciencia del Clima y Resiliencia CR2 Explorador Climático. Available online: http://explorador.cr2.cl/ (accessed on 30 January 2018).

32. Valdés-Pineda, R.; Pizarro, R.; García-Chevesich, P.; Valdés, J.B.; Olivares, C.; Vera, M.; Balocchi, F.; Pérez, F.; Vallejos, C.; Fuentes, R.; et al. Water governance in Chile: Availability, management and climate change. J. Hydrol. 2014, 519, 2538-2567. [CrossRef]

33. Sidibe, M.; Dieppois, B.; Mahé, G.; Paturel, J.E.; Amoussou, E.; Anifowose, B.; Lawler, D. Trend and variability in a new, reconstructed streamflow dataset for West and Central Africa, and climatic interactions, 1950-2005. J. Hydrol. 2018, 561, 478-493. [CrossRef]

34. Moriasi, D.N.; Gitau, M.W.; Pai, N.; Daggupati, P. Hydrologic and Water Quality Models: Performance Measures and Evaluation Criteria. Trans. ASABE 2015, 58, 1763-1785.

35. Kling, H.; Fuchs, M.; Paulin, M. Runoff conditions in the upper Danube basin under an ensemble of climate change scenarios. J. Hydrol. 2012, 424-425, 264-277. [CrossRef]

36. U.S. Department of the Interior. U.S.G.S. Earth Explorer. Available online: https://earthexplorer.usgs.gov/ (accessed on 1 December 2017).

37. Palla, A.; Gnecco, I.; La Barbera, P.; Ivaldi, M.; Caviglia, D. An Integrated GIS Approach to Assess the Mini Hydropower Potential. Water Resour. Manag. 2016, 30, 2979-2996. [CrossRef]

38. Yousuf, I.; Ghumman, A.R.; Hashmi, H.N. Optimally sizing small hydropower project under future projected flows. KSCE J. Civ. Eng. 2017, 21, 1964-1978. [CrossRef]

39. Mann, H.B. Nonparametric Tests Against Trend. Econometrica 1945, 13, 245-259. [CrossRef]

40. Kendall, M.G. Rank Correlation Methods. Br. J. Stat. Psychol. 1956, 9, 68. [CrossRef]

41. Yue, S.; Pilon, P.; Cavadias, G. Power of the Mann-Kendall and Spearman's rho tests for detecting monotonic trends in hydrological series. J. Hydrol. 2002, 259, 254-271. [CrossRef]

42. Kulkarni, A.; Storch, H. Von Monte Carlo experiments on the effect of serial correlation on the Mann-Kendall test of trend. Meteorol. Z. 1995, 4, 82-85. [CrossRef]

43. Yue, S.; Wang, C.Y. Applicability of prewhitening to eliminate the influence of serial correlation on the Mann-Kendall test. Water Resour. Res. 2002, 38, 4:1-4:7. [CrossRef]

44. Sneyers, R. On the Statistical Analysis of Series of Observations; Technical Note No. 143; World Meteorological Organization: Geneva, Switzerland, 1990; ISBN 9263104158.

45. Sen, P.K. Estimates of the Regression Coefficient Based on Kendall's Tau. J. Am. Stat. Assoc. 1968, 63, 1379-1389. [CrossRef]

46. McCabe, G.J.; Wolock, D.M. A step increase in streamflow in the conterminous United States. Geophys. Res. Lett. 2002, 29, 38:1-38:4. [CrossRef]

47. Liebmann, B.; Dole, R.M.; Jones, C.; Bladé, I.; Allured, D. Influence of choice of time period on global surface temperature trend estimates. Bull. Am. Meteorol. Soc. 2010, 91, 1485-1491. [CrossRef]

48. Mantua, N.J.; Hare, S.R. The Pacific Decadal Oscillation. J. Oceanogr. 2009, 58, 35-44. [CrossRef]

49. Trenberth, K.E. The definition of El Nino-ProQuest. Bull. Am. Meteorol. Soc. 1997, 78, 2771-2777. [CrossRef]

50. Marshall, G. Trends in the Southern Annular Mode from Observation and Reanalysis. J. Clim. 2003, 16, 4134-4143. [CrossRef]

51. Enfield, D.B.; Mestas-Nuñez, A.M.; Trimble, P.J. The Atlantic multidecadal oscillation and its relation to rainfall and river flows in the continental U.S. Geophys. Res. Lett. 2001, 28, 2077-2080. [CrossRef] 
52. Huang, B.; Banzon, V.F.; Freeman, E.; Lawrimore, J.; Liu, W.; Peterson, T.C.; Smith, T.M.; Thorne, P.W.; Woodruff, S.D.; Zhang, H.M. Extended reconstructed sea surface temperature version 4 (ERSST.v4). Part I: Upgrades and intercomparisons. J. Clim. 2015, 28, 911-930. [CrossRef]

53. Huang, B.; Thorne, P.W.; Banzon, V.F.; Boyer, T.; Chepurin, G.; Lawrimore, J.H.; Menne, M.J.; Smith, T.M.; Vose, R.S.; Zhang, H.M. Extended reconstructed Sea surface temperature, Version 5 (ERSSTv5): Upgrades, validations, and intercomparisons. J. Clim. 2017, 30, 8179-8205. [CrossRef]

54. Taylor, K.E.; Stouffer, R.J.; Meehl, G.A. An overview of CMIP5 and the experiment design. Bull. Am. Meteorol. Soc. 2012, 93, 485-498. [CrossRef]

55. Moss, R.H.; Edmonds, J.A.; Hibbard, K.A.; Manning, M.R.; Rose, S.K.; Van Vuuren, D.P.; Carter, T.R.; Emori, S.; Kainuma, M.; Kram, T.; et al. The next generation of scenarios for climate change research and assessment. Nature 2010, 463, 747-756. [CrossRef] [PubMed]

56. Barnett, T.P. Comparison of near-surface air temperature variability in 11 coupled global climate models. J. Clim. 1999, 12, 511-518. [CrossRef]

57. Benestad, R.E. A comparison between two empirical downscaling strategies. Int. J. Clim. 2001, 21, $1645-1668$. [CrossRef]

58. Lorenz, E.N. Empirical Orthogonal Functions and Statistical Weather Prediction; Science Report 1, Statistical Forecasting Project; Massachusetts Institute of Technology, Department of Meteorology: Cambridge, MA, USA, 1956; Volume 1, p. 52.

59. Akaike, H. A new look at the statistical model identification. IEEE Trans. Automat. Contr. 1974, 19, 716-723. [CrossRef]

60. Benestad, R.E. The cause of warming over Norway in the ECHAM4/OPYC3 GHG integration. Int. J. Climatol. 2001, 21, 371-387. [CrossRef]

61. Muñoz, A.A.; González-Reyes, A.; Lara, A.; Sauchyn, D.; Christie, D.; Puchi, P.; Urrutia-Jalabert, R.; Toledo-Guerrero, I.; Aguilera-Betti, I.; Mundo, I.; et al. Streamflow variability in the Chilean Temperate-Mediterranean climate transition $\left(35^{\circ} \mathrm{S}-42^{\circ} \mathrm{S}\right)$ during the last 400 years inferred from tree-ring records. Clim. Dyn. 2016, 47, 4051-4066. [CrossRef]

62. Quintana, J.M.; Aceituno, P. Changes in the rainfall regime along the extratropical west coast of south America (Chile): $30-43^{\circ} \mathrm{S}$. Atmósfera 2012, 25, 1-22.

63. Valdés-Pineda, R.; Valdés, J.B.; Diaz, H.F.; Pizarro-Tapia, R. Analysis of spatio-temporal changes in annual and seasonal precipitation variability in South America-Chile and related ocean-atmosphere circulation patterns. Int. J. Climatol. 2016, 36, 2979-3001. [CrossRef]

64. Rubio-Álvarez, E.; McPhee, J. Patterns of spatial and temporal variability in streamflow records in south central Chile in the period 1952-2003. Water Resour. Res. 2010, 46,1-16. [CrossRef]

65. Cortés, G.; Vargas, X.; McPhee, J. Climatic sensitivity of streamflow timing in the extratropical western Andes Cordillera. J. Hydrol. 2011, 405, 93-109. [CrossRef]

66. Montecinos, A.; Aceituno, P. Seasonality of the ENSO-related rainfall variability in central Chile and associated circulation anomalies. J. Clim. 2003, 16, 281-296. [CrossRef]

67. Valdés-Pineda, R.; Cañón, J.; Valdés, J.B. Multi-decadal 40- to 60-year cycles of precipitation variability in Chile (South America) and their relationship to the AMO and PDO signals. J. Hydrol. 2018, 556, 1153-1170. [CrossRef]

68. Gillett, N.P.; Kell, T.D.; Jones, P.D. Regional climate impacts of the Southern Annular Mode. Geophys. Res. Lett. 2006, 33, 1-4. [CrossRef]

69. Chen, C.; Cane, M.A.; Wittenberg, A.T.; Chen, D. ENSO in the CMIP5 Simulations: Life Cycles, Diversity, and Responses to Climate Change. J. Clim. 2017, 30, 775-801. [CrossRef]

(C) 2019 by the authors. Licensee MDPI, Basel, Switzerland. This article is an open access article distributed under the terms and conditions of the Creative Commons Attribution (CC BY) license (http://creativecommons.org/licenses/by/4.0/). 